\title{
Utilização experimental de hidroxiapatita sintética em alvéolos dentários de gatos domésticos (Felis catus): estudo clínico, radiográfico e histomorfométrico
}

\author{
[Experimental application of hydroxyapatite in feline (Felis catus) dental sockets: Clinic, radiographic, \\ histologic and histomorphometric studies] \\ E.C. Silva ${ }^{1}$, A.P.B. Borges ${ }^{1}$, C.D. Neves ${ }^{1}$, E.C. Carlo $^{1}$, R.E. Barros ${ }^{1}$, M.C.F.N.S. Hage ${ }^{1}$, \\ R.L. de Souza ${ }^{2}$, M.A. Souza ${ }^{2}$, H.S. Barud ${ }^{3}$, S.M.C.M. Bicalho ${ }^{4}$ \\ ${ }^{1}$ Universidade Federal de Viçosa - Viçosa, MG \\ ${ }^{2}$ Universidade Federal de Mato Grosso - Cuiabá, MT \\ ${ }^{3}$ Universidade Estadual Paulista Júlio de Mesquita Filho - Araraquara, SP \\ ${ }^{4}$ JHS Laboratório Químico - Sabará, MG \\ RESUMO
}

\begin{abstract}
A fim de avaliar a resposta biológica da hidroxiapatita sintética (HAP-91) nos alvéolos de felinos domésticos, este biomaterial foi implantado após extração do terceiro pré-molar inferior direito em 12 gatos e mantida por meio de uma membrana de celulose bacteriana. No lado esquerdo, os alvéolos foram apenas recobertos com a membrana de celulose bacteriana, formando o grupo-controle. Observou-se, durante a avaliação clínica, que todos os animais voltaram a comer normalmente ração úmida, sem apresentarem sinais de dor ou desconforto após a recuperação anestésica. A cicatrização da ferida cirúrgica ocorreu de forma satisfatória, sendo que a membrana de celulose bacteriana evitou a saída precoce da hidroxiapatita. Radiograficamente, aos 50 dias, todos os animais apresentaram radiopacidade óssea homogênea em ambos os lados. À análise histomorfométrica, observou-se adiantamento do processo de reparo do osso alveolar nos oito primeiros dias do grupo-tratado quando comparado ao grupo-controle, bem como atraso aos 30 dias, porém, aos 50 dias, ambos os grupos apresentavam porcentagem de tecido ósseo semelhante e morfologicamente normal. Os resultados sugerem que a hidroxiapatita é biocompatível, integra-se ao tecido ósseo alveolar e pode ser utilizada em felinos.
\end{abstract}

Palavras-chave: gato, hidroxiapatita sintética, alvéolo, membrana de celulose bacteriana

\begin{abstract}
The biocompatibility of a material depends on its characteristics, as well as the species and the environment recipient. In order to evaluate the biological response of the synthetic hydroxyapatite (HAP91) in feline dental alveoli, it was implanted in the right inferior third premolar after extraction in 12 cats and maintained through a bacterial cellulose membrane. On the left side the alveoli was covered with a bacterial cellulose membrane (control group). During clinical evaluations it was observed that the animals started to eat after the anesthetic recovery time, without clinical signs of pain. There was a satisfactory cicatrization of the surgical wound and the bacterial cellulose membrane aided in repairing the gum, avoiding the loss of the hydroxyapatite. Radiographs taken 50 days post surgery presented homogeneous bone radiopacity on both sides. The histological and histomorfometrical analysis showed a positive progress of the alveolar repair in the first 8 days in the treated group when compared to the control group and a delay at 30 days, however at 50 days both presented a similar and morphologically normal percentage of bone tissue. These findings suggest that HAP-91 is biocompatible and integrates into the feline alveolar bone.
\end{abstract}

Keywords: syntetic hydroxyapatite, alveoli, domestic cat, bacterial cellulose membrane

Recebido em 9 de março de 2011

Aceito em 23 de março de 2012

E-mail: erotidescs@yahoo.com.br 


\section{INTRODUÇÃO}

Existem desafios na odontologia em se encontrar biomateriais ideais na substituição óssea para tratamentos diversos, como defeitos ósseos, aumento do rebordo alveolar, lesões osteoporóticas e deformidades maxilofaciais (Zenóbio et al., 1998). $\mathrm{Na}$ odontologia veterinária, o maior desafio está relacionado à perda do osso alveolar, sendo principalmente a doença periodontal e os traumas acidentais e/ou cirúrgicos ocasionados por extrações dentárias algumas das mais frequentes causas de perda óssea (Emily et al., 1999; Duarte et al., 2006). Como substituto ósseo, tanto na odontologia como na ortopedia, a cerâmica de fosfato de cálcio é um dos biomateriais mais utilizados dentre as cerâmicas, por apresentar similaridade com a matriz óssea em sua composição (Pereira et al., 2006) e por ser biocompatível, não tóxica e bem tolerada pelos pacientes (Arakaki et al., 1995). Com base nos fatos expostos anteriormente, conjecturou-se, neste estudo, que o implante de hidroxiapatita sintética (HAP-91) poderia ser empregado como biomaterial em odontologia felina e utilizado como alternativa na prevenção da reabsorção óssea pós-exodontia. Foi objetivo do presente trabalho avaliar: i) o comportamento biológico da hidroxiapatita sintética implantada em alvéolos de felinos domésticos; ii) a reparação óssea pós-exodontia; e iii) a biocompatibilidade da HAP-91 em alvéolos de felinos.

\section{MATERIAL E MÉTODOS}

Foram utilizados 12 gatos, sem raça definida, machos e fêmeas, sadios, castrados aos oito meses, de aproximadamente dois anos de idade ao início do estudo. Os gatos foram mantidos em condições homogêneas de alimentação, manejo sanitário profilático e instalações desde os 45 dias após o nascimento, sendo alojados em gatil experimental. $\mathrm{O}$ presente estudo foi submetido à apreciação do comitê de bioética do Departamento de Veterinária da Universidade Federal de Viçosa e realizado de acordo com as normas exigidas.

Após exames pré-cirúrgicos, todos os animais receberam $20 \mathrm{mg} / \mathrm{kg}$ de amoxicilina e foram mantidos em jejum sólido e líquido. Previamente à cirurgia, foi realizada radiografia no local do dente a ser extraído, utilizando-se a técnica do paralelismo, para observar a morfologia da raiz e a radiopacidade do osso alveolar. Após descarte de anormalidades da cavidade oral, os animais foram intubados e a anestesia de manutenção foi realizada com inalação de isoflurano, associado a um bloqueio do nervo mandibular, em ambos os lados. Após antissepsia da cavidade oral com gluconato de clorexidina $0,12 \%$, realizou-se a exodontia dos terceiros pré-molares direito e esquerdo, sendo que o lado direito foi considerado o grupo-tratado, e o lado esquerdo o grupo-controle. Após a extração, a altura da crista do osso alveolar foi mensurada por meio de um paquímetro.

O espaço alveolar do dente pré-molar inferior direito extraído foi totalmente preenchido com a hidroxiapatita HAP-91 e, para evitar a sua saída e auxiliar a cicatrização da gengiva, os alvéolos foram recobertos com uma membrana de celulose bacteriana (Fig. 1). Em seguida, o retalho mucoperiosteal foi suturado com ponto interrompido simples, utilizando-se fio catgut 4-0. Já o alvéolo do dente pré-molar inferior esquerdo extraído foi preenchido pelo coágulo que se forma normalmente, e também recoberto com a membrana de celulose bacteriana. As cúspides dos terceiros pré-molares superiores direito e esquerdo foram desgastadas, a fim de evitar atrito com os pontos de sutura.

Os cuidados pós-operatórios se resumiram em: administração de sulfato de morfina por três dias consecutivos e amoxicilina durante sete dias, alimentação com ração comercial umedecida e carne bovina moída duplamente, água à vontade e manutenção do colar elizabetano por 45 dias. A avaliação clínica constou da observação diária da ferida cirúrgica, observando-se a intensidade da reação inflamatória por meio da alteração do volume local (edema), que foi classificado em: grau 1) edema discreto; grau 2) edema moderado; e grau 3) edema intenso. Avaliou-se também a sensibilidade à dor pelo comportamento do animal, bem como a presença de secreção purulenta e a deiscência de sutura.

Radiografias das regiões operadas foram realizadas imediatamente após a cirurgia e aos oito, 21, 30 e 50 dias de pós-operatório, objetivando-se avaliar o processo de reparação dos alvéolos. As radiografias foram analisadas quanto à radiopacidade local em diferentes graus (de 0 a 4): grau 0 ) menor radiopacidade alveolar, 
equivalente radiograficamente à radiopacidade de um espaço alveolar logo após a extração dentária; grau 1) maior radiopacidade do alvéolo quando comparado ao grau 0 , porém ainda intensamente abaixo da radiopacidade óssea alveolar felina; grau 2) opacidade discreta do alvéolo do dente extraído, comparando-se ao osso alveolar felino; grau 3) radiopacidade do alvéolo do dente extraído semelhante à radiopacidade óssea alveolar felina; e grau 4) radiopacidade do dente extraído maior que a do osso alveolar felino, equivalente radiograficamente à radiopacidade da hidroxiapatita. Avaliou-se, ainda, a presença de radioluscência peri-implante e a reabsorção do osso alveolar, classificado como presente ou ausente.

Foram realizadas também análises histológicas da membrana de celulose bacteriana e dos alvéolos por meio de biópsias excisionais de ambos os grupos. Para tal, os gatos foram divididos em três subgrupos. No grupo $1(n=4)$, as biópsias foram realizadas aos oito dias; no grupo $2(n=4)$, aos 30 dias; e no grupo $3(n=4)$, aos 50 dias. As amostras alveolares obtidas foram fixadas, desmineralizadas, processadas para análise histológica e coradas pelo método de hematoxilina e eosina (HE). Os materiais foram analisados qualitativamente (caracterizando tecidos e células presentes em cada amostra) e quantitativamente (por meio da contagem de pontos sobre tecido conjuntivo, tecido ósseo e hidroxiapatita) pela microscopia óptica.

Empregou-se o método de análise de variáveis não paramétricas de Kruskal-Wallis com $\mathrm{P}<0,05$.

\section{RESULTADOS E DISCUSSÃO}

Na avaliação clínica pós-operatória, nenhum animal apresentou alterações no comportamento indicativo de dor, apresentando apenas um edema discreto (grau 1) nos sete primeiros dias, possivelmente em decorrência do trauma cirúrgico, o que leva a crer que a HAP-91 e a membrana de celulose bacteriana foram bem toleradas pelos tecidos bucais. Apesar da deiscência em $33 \%$ dos gatos, provavelmente devido ao constante trauma da língua áspera do gato sobre a sutura, a membrana manteve-se aderida à gengiva entre oito e 21 dias, evitandose a exposição óssea e a evasão da HAP-91.

Não foi observada, após a extração até os 50 dias de avaliação, diminuição da crista em ambos os grupos, provavelmente devido ao tempo insuficiente para observar tal fato ou à utilização da membrana de celulose bacteriana, que pode prevenir deformidades ósseas (Novaes Júnior et al., 2002). O pós-operatório radiográfico imediato se caracterizou, no grupo-controle, por radiopacidade grau 0 (Fig. 2) e, no grupo tratado com a HAP-91, por grau 4 (Fig. 3) devido a seu alto número atômico (Borges et al., 2000; Duarte, 2003). Houve intensa variação de graus, em ambos os grupos, entre o oitavo e o $30^{\circ}$ dia entre as regiões, sendo que, aos 50 dias, tanto o grupo tratado quanto o controle apresentaram quadro semelhante, caracterizado por grau $3 \mathrm{em}$ todos os alvéolos, em consequência da reparação tecidual com presença de tecido ósseo em ambos os grupos.

Comparando-se as diferentes regiões dos alvéolos do grupo-controle (coronal, média e apical), não houve diferença significativa em nenhuma data, demonstrando que o aumento da radiopacidade ocorreu de forma semelhante em todas as regiões em um mesmo período (Tab. 1). No grupo-tratado, a reparação do alvéolo também ocorreu de forma semelhante em todas as regiões, exceto aos 21 dias, quando a região apical mostrou estar em grau mais adiantado comparada à região coronal. Neste mesmo grupo, houve uma diminuição significativa do grau de radiopacidade entre o oitavo e o $30^{\circ}$ dia, sugerindo a biodegradação da hidroxiapatita e consequente deposição de tecido fibrovascular. Comparando-se 30 e 50 dias, houve aumento significativo nas regiões coronal e média, devido à provável formação óssea (Tab. 2). Na região apical, não houve diferença significativa, isto é, o grau permaneceu semelhante em todos os momentos (grau 3). Isto pode ser devido à proximidade da região com o delta apical, local de maior fluxo sanguíneo, em virtude da grande vascularização, ocorrendo uma maior degradação da HAP-91, simultaneamente à neoformação óssea, mantendo, assim, radiopacidade constante. 
Tabela 1. Média e desvio-padrão da classificação da radiopacidade (graus) do grupo- controle em todas as regiões aos oito, 21, 30 e 50 dias após cirurgia experimental

\begin{tabular}{clll} 
Dias & Coronal & Média & Apical \\
\hline & Ambos os alvéolos & Ambos os alvéolos & Ambos os alvéolos \\
8 & $0,25 \pm 0,45 \mathrm{~A}$ & $0,25 \pm 0,45 \mathrm{~A}$ & $0,25 \pm 0,45 \mathrm{~A}$ \\
21 & $1,66 \pm 0,51 \mathrm{~A}$ & $1,83 \pm 0,4 \mathrm{~A}$ & $2,17 \pm 0,40 \mathrm{~A}$ \\
30 & $2,5 \pm 0,54 \mathrm{~A}$ & $2,5 \pm 0,54 \mathrm{~A}$ & $2,5 \pm 0,54 \mathrm{~A}$ \\
50 & $3,0 \pm 0,33 \mathrm{~A}$ & $3,0 \pm 0,33 \mathrm{~A}$ & $3,0 \pm 0,33 \mathrm{~A}$
\end{tabular}

Letras maiúsculas iguais na mesma linha sinalizam semelhança entre os grupos pelo teste Mann-Whitney $(\mathrm{P}<0,05)$.

Tabela 2. Média e desvio-padrão da classificação da radiopacidade (graus) do grupo- tratado em todas as regiões aos oito, 21, 30 e 50 dias após cirurgia experimental (exodontia)

\begin{tabular}{|c|c|c|c|c|c|c|}
\hline \multirow{2}{*}{ Dias } & \multicolumn{2}{|c|}{ Coronal } & \multicolumn{2}{|c|}{ Média } & \multicolumn{2}{|c|}{ Apical } \\
\hline & $1^{\circ}$ & $2^{\circ}$ & $1^{\circ}$ & $2^{\circ}$ & $1^{\circ}$ & $2^{\circ}$ \\
\hline \multirow[t]{2}{*}{8} & $2,83 \pm$ & $3,22 \pm$ & $3,33 \pm$ & $3,50 \pm$ & $3,08 \pm$ & $3,0 \pm$ \\
\hline & $1,52 \mathrm{aA}$ & $1,54 \mathrm{aA}$ & $0,77 \mathrm{aA}$ & $0,52 \mathrm{aA}$ & $0,51 \mathrm{aA}$ & $0,42 \mathrm{aA}$ \\
\hline \multirow[t]{2}{*}{21} & $2,33 \pm$ & $2,0 \pm$ & $2,5 \pm$ & $3,0 \pm$ & $3,0 \pm$ & $3,0 \pm$ \\
\hline & $0,51 \mathrm{aA}$ & $0,89 \mathrm{aA}$ & $0,54 \mathrm{bAB}$ & $0,63 \mathrm{bAB}$ & $0,32 \mathrm{aB}$ & $0,32 \mathrm{aB}$ \\
\hline \multirow[t]{2}{*}{30} & $2,0 \pm$ & $2,0 \pm$ & $2,2 \pm$ & $2,2 \pm$ & $3,0 \pm$ & $3,0 \pm$ \\
\hline & $0,70 \mathrm{bA}$ & $0,70 \mathrm{bA}$ & $0,44 \mathrm{bA}$ & $0,44 \mathrm{bA}$ & $0,00 \mathrm{aA}$ & $0,00 \mathrm{aA}$ \\
\hline \multirow[t]{2}{*}{50} & $3,0 \pm$ & $3,0 \pm$ & $3,0 \pm$ & $3,0 \pm$ & $3,0 \pm$ & $3,0 \pm$ \\
\hline & $0,00 \mathrm{cA}$ & $0,00 \mathrm{cA}$ & $0,00 \mathrm{cA}$ & $0,00 \mathrm{cA}$ & $0,00 \mathrm{aA}$ & $0,00 \mathrm{aA}$ \\
\hline
\end{tabular}

Letras minúsculas diferentes na mesma coluna sinalizam diferença significante entre os dias pelo teste MannWhitney $(\mathrm{P}<0,05)$. Letras maiúsculas iguais na mesma linha sinalizam semelhança entre as regiões pelo teste MannWhitney $(\mathrm{P}<0,05)$.

Comparando-se as respectivas regiões dos grupos tratado e controle, não houve diferença significativa aos 30 e 50 dias, isto é, aos 30 dias os grupos tratado e controle já apresentavam radiopacidade semelhantes (Tab. 3). O tempo necessário para a regeneração óssea completa não foi menor com a presença da HAP-91, o que está de acordo com Duarte 2003.

Tabela 3. Média e desvio-padrão da classificação da radiopacidade (graus) do grupo- tratado em comparação ao grupo-controle em todas as regiões aos oito, 21, 30 e 50 dias após cirurgia experimental (exodontia)

\begin{tabular}{|c|c|c|c|c|c|c|c|c|c|}
\hline \multirow{3}{*}{$\frac{\text { Grupo }}{\text { Dias }}$} & \multicolumn{3}{|c|}{ Coronal } & \multicolumn{3}{|c|}{ Média } & \multicolumn{3}{|c|}{ Apical } \\
\hline & \multirow{2}{*}{$\begin{array}{c}\text { Controle } \\
\text { Ambos }\end{array}$} & \multicolumn{2}{|c|}{ Tratado } & \multirow{2}{*}{$\begin{array}{c}\text { Controle } \\
\text { Ambos }\end{array}$} & \multicolumn{2}{|c|}{ Tratado } & \multirow{2}{*}{$\begin{array}{c}\text { Controle } \\
\text { Ambos }\end{array}$} & \multicolumn{2}{|c|}{ Tratado } \\
\hline & & $1^{\circ}$ & $2^{\circ}$ & & $1^{\circ}$ & $2^{\circ}$ & & $1^{\circ}$ & $2^{\circ}$ \\
\hline \multirow[t]{2}{*}{8} & $0,25 \pm$ & $2,83 \pm$ & $3,22 \pm$ & $0,25 \pm$ & $3,33 \pm$ & $3,50 \pm$ & $0,25 \pm$ & $3,08 \pm$ & $3,0 \pm$ \\
\hline & $0,45 \mathrm{~A}$ & $1,52 \mathrm{~B}$ & $1,54 \mathrm{~B}$ & $0,45 \mathrm{~A}$ & $0,77 \mathrm{~B}$ & $0,52 \mathrm{~B}$ & $0,45 \mathrm{~A}$ & $0,51 \mathrm{~B}$ & $0,42 \mathrm{~B}$ \\
\hline \multirow[t]{2}{*}{21} & $1,66 \pm$ & $2,33 \pm$ & $2,0 \pm$ & $1,83 \pm$ & $2,5 \pm$ & $3,0 \pm$ & $2,17 \pm$ & $3,0 \pm$ & $3,0 \pm$ \\
\hline & $0,51 \mathrm{~A}$ & $0,51 \mathrm{~B}$ & $0,89 \mathrm{~B}$ & $0,4 \mathrm{bA}$ & $0,54 \mathrm{~B}$ & $0,63 \mathrm{~B}$ & $0,40 \mathrm{~A}$ & $0,32 \mathrm{~B}$ & $0,32 \mathrm{~B}$ \\
\hline \multirow[t]{2}{*}{30} & $2,5 \pm$ & $2,0 \pm$ & $2,0 \pm$ & $2,5 \pm$ & $2,2 \pm$ & $2,2 \pm$ & $2,5 \pm$ & $3,0 \pm$ & $3,0 \pm$ \\
\hline & $0,54 \mathrm{~A}$ & $0,70 \mathrm{~A}$ & $0,70 \mathrm{~A}$ & $0,54 \mathrm{~A}$ & $0,44 \mathrm{~A}$ & $0,44 \mathrm{~A}$ & $0,54 \mathrm{~A}$ & $0,00 \mathrm{~A}$ & $0,00 \mathrm{~A}$ \\
\hline \multirow[t]{2}{*}{50} & $3,0 \pm$ & $3,0 \pm$ & $3,0 \pm$ & $3,0 \pm$ & $3,0 \pm$ & $3,0 \pm$ & $3,0 \pm$ & $3,0 \pm$ & $3,0 \pm$ \\
\hline & $0,00 \mathrm{~A}$ & $0,00 \mathrm{~A}$ & $0,00 \mathrm{~A}$ & $0,00 \mathrm{~A}$ & $0,00 \mathrm{~A}$ & $0,00 \mathrm{~A}$ & $0,00 \mathrm{~A}$ & $0,00 \mathrm{~A}$ & $0,00 \mathrm{~A}$ \\
\hline
\end{tabular}

Letras maiúsculas diferentes na mesma linha, numa mesma região, sinalizam diferença significante pelo teste MannWhitney $(\mathrm{P}<0,05)$. 
Foi observado um halo de radiotransparência no alvéolo circundando o centro mais radiopaco durante a reparação óssea nos animais tratados, provavelmente devido à substituição da HAP-91 pelo tecido fibrovascular e não perceptível ao exame radiográfico (Borges et al., 2000; Duarte, 2003). Um animal apresentou reabsorção óssea alveolar (Fig. 4) e, apesar da contaminação local ser sugerida como causa devido ao difícil controle bacteriano (Lins et al., 2006), acreditase que, nesse experimento, o quadro se deveu a uma resposta inerente ao animal, uma vez que Resende (2006) cita a possibilidade de haver diferentes respostas do organismo em relação aos biomateriais entre espécies diferentes e dentro da mesma espécie.

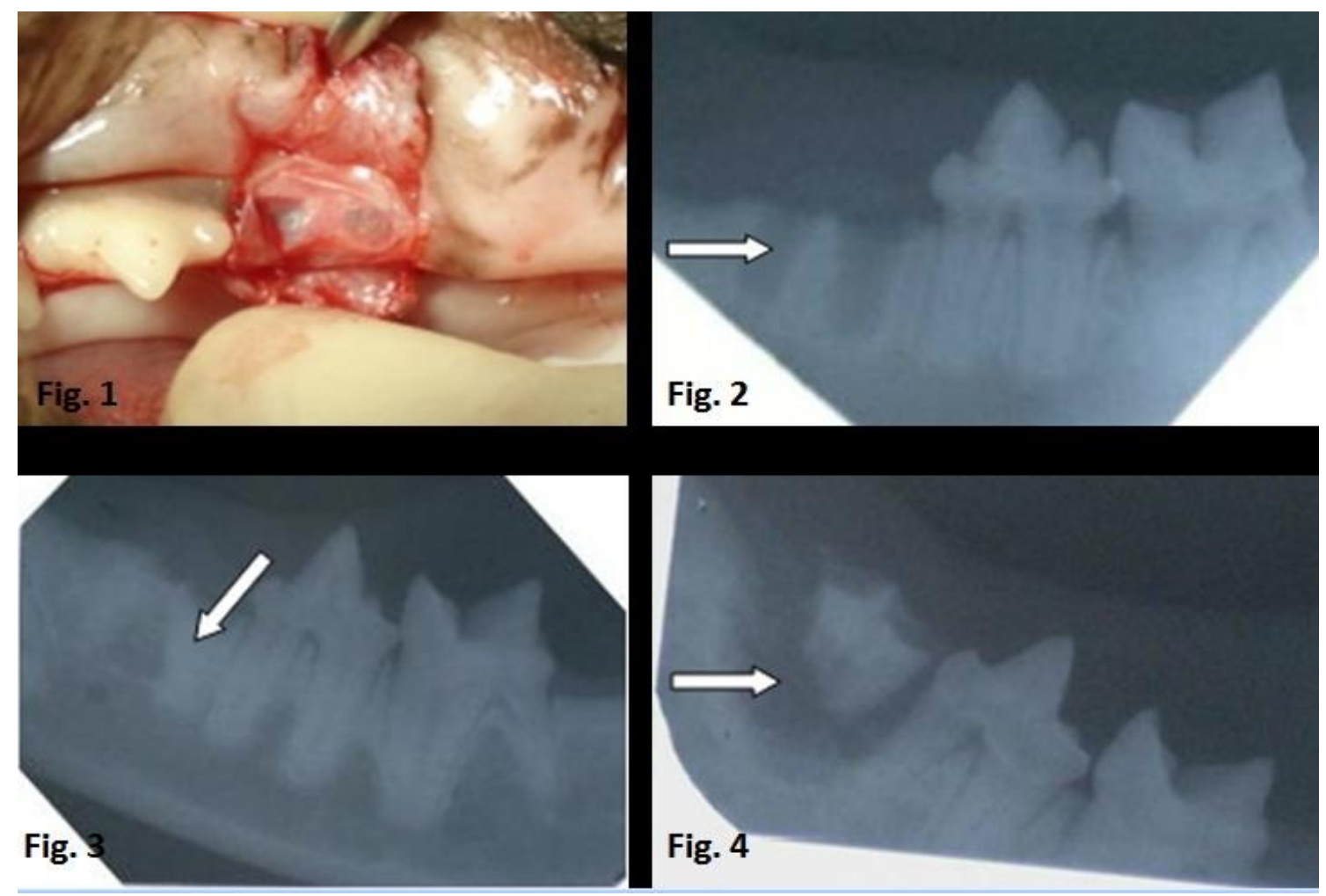

Figura 1. Cobertura dos alvéolos dentários com a membrana de celulose bacteriana após extração do dente pré-molar inferior direito de gato (Felis catus), para evitar a saída da HAP-91. Figura 2. Radiografia da arcada dentária mandibular esquerda (grupo-controle) de gato (Felis catus) submetido à cirurgia experimental no pós-operatório imediato mostrando a radiopacidade grau 0. Figura 3. Radiografia da arcada dentária mandibular direita (grupotratado) de gato (Felis catus) submetido à cirurgia experimental no pós-operatório imediato mostrando a radiopacidade grau 4. Figura 4. Reabsorção óssea alveolar observada em um dos gatos do grupo-tratado (contendo a HAP-91 e a membrana de celulose bacteriana) aos 21 dias após exodontia do pré-molar inferior direito.

À análise histológica, aos oito dias, observou-se, no grupo-tratado, tecido de granulação caracterizado pela proliferação fibroblástica e angioblástica, com algumas áreas de tecido ósseo neoformado, apresentando áreas de interface contínua entre eles. Houve proliferação de tecido ósseo em torno dos cristais de HAP-91 e um processo de remodelação em suas margens, com osteoblastos superficiais. Neutrófilos maduros e não degenerados foram encontrados em grande quantidade, provavelmente devido ao ambiente altamente contaminado da cavidade oral. Foi observada também neste grupo grande quantidade de linfócitos jovens e maduros, provavelmente devido à presença da membrana de celulose bacteriana, que apresentou, neste período, sugestivo material proteináceo, além da substância fibrilar organizada em camadas e de detritos celulares de origem inflamatória (Fig. 5).

No mesmo período, no grupo-controle (8 dias), pôde-se observar um preenchimento do alvéolo por tecido de granulação (Fig. 6) com intensa infiltração de fibroblastos, infiltrado 
polimorfonuclear (neutrófilo) moderado e difuso (Fig. 7). Também houve presença de linfócitos jovens e maduros e poucas áreas de tecido ósseo imaturo. Não foram observados sinais de reabsorção do osso alveolar, como irregularidades das bordas do defeito ou superfície. Aos 21 dias, a membrana apresentava projeções papilares (vegetações) com detritos celulares de origem inflamatória com áreas multifocais basofílicas, compatíveis com colônias bacterianas (Fig. 8), o que provavelmente causou a sua expulsão posteriormente.

Aos 30 dias, no grupo-controle, observou-se proliferação de tecido conjuntivo com predomínio de população fibroblástica e vascularização, em torno de trabéculas ósseas. $\mathrm{O}$ espaço alveolar encontrava-se com infiltrado inflamatório polimorfonuclear discreto a moderado (Fig. 9). Já no grupo-tratado, neste mesmo período, observaram-se proliferação celular osteoblástica em torno dos cristais de HAP-91, tecido ósseo neoformado, hemácias, alguns macrófagos e infiltrado inflamatório polimorfonuclear (neutrófilos) acentuado, sendo que este último foi possivelmente devido à constante contaminação da cavidade oral, uma vez que tal fato também foi encontrado no grupo- controle. Porém, a presença de HAP-91 associada à contaminação favoreceu o processo inflamatório, pois a hidroxiapatita é susceptível à digestão bacteriana (Roush, 2007), sendo observadas, neste experimento, algumas áreas onde a HAP-91 se apresentava envolvida por tecido granulomatoso com proliferação fibrovascular, presença de osteonecrose, associado também a infiltrado inflamatório polimorfonuclear (neutrófilos) acentuado (Fig. 10).

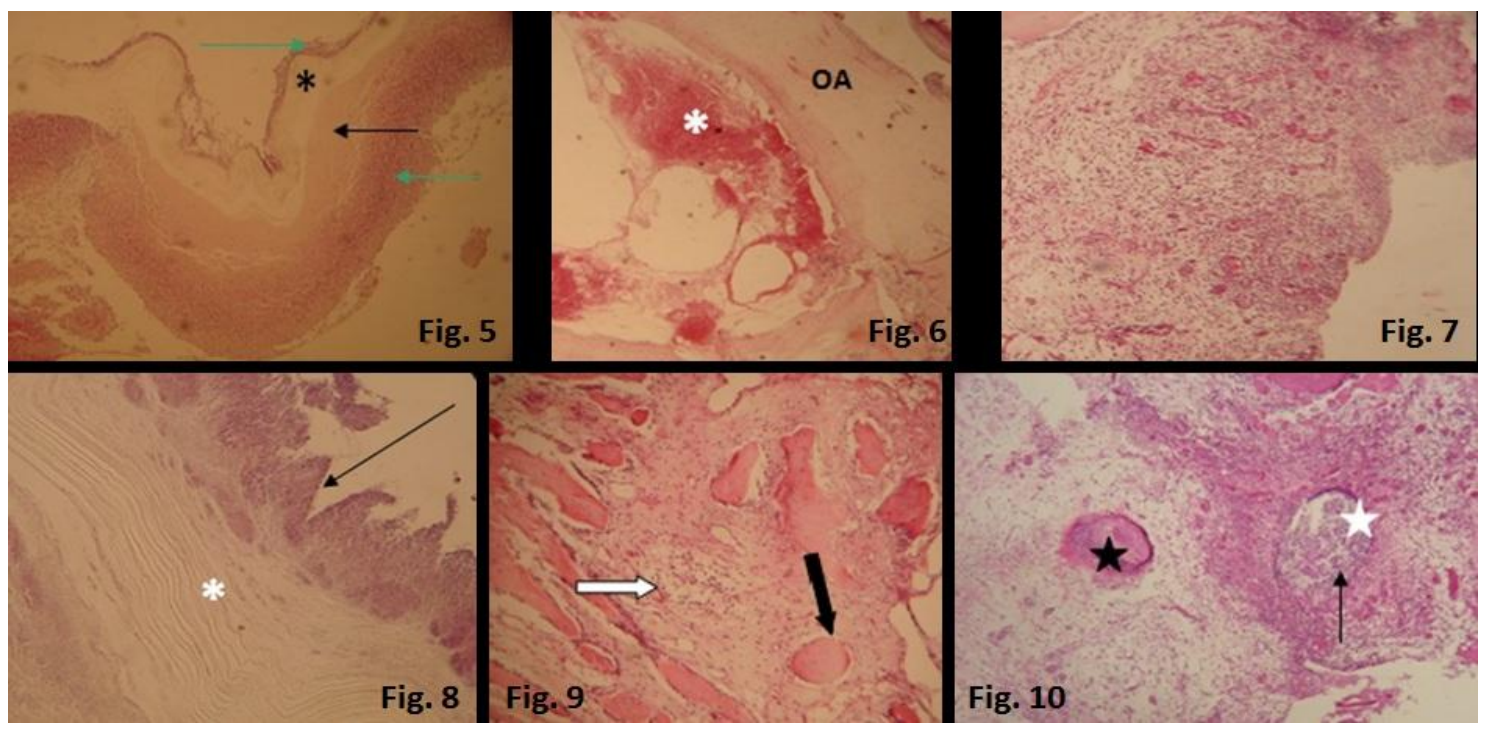

Figura 5. Imagem histológica da membrana de celulose bacteriana extraída aos oito dias de pós-operatório. Substância fibrilar organizada em camadas (asterisco); material proteináceo aderido na substância fibrilar (seta negra); detritos celulares de origem inflamatória (setas verdes). Corte longitudinal, 40X. Figura 6. Imagem histológica do alvéolo dentário do grupo-controle aos oito dias pós-exodontia. Observa-se proliferação fibrovascular (tecido de granulação) (estrela) próxima ao osso alveolar (OA). Corte transversal, 40X. Figura 7. Imagem histológica do alvéolo dentário do grupo-controle aos oito dias pós-exodontia. Observa-se proliferação fibrovascular (tecido de granulação) com intensa infiltração de fibroblastos e matriz extracelular imatura; infiltrado polimorfonuclear (neutrófilos) moderado a difuso. Corte longitudinal, 100X. Figura 8: Imagem histológica da membrana de celulose bacteriana aos 21 dias de pós-operatório. Observa-se substância fibrilar organizada em camadas (estrela branca); projeções papilares com detritos celulares de origem inflamatória com áreas multifocais basofílicas compatíveis com colônias bacterianas (seta). Corte longitudinal, 100X. Figura 9. Imagem histológica do alvéolo dentário do grupocontrole aos 30 dias mostrando a proliferação de tecido conjuntivo (seta preta) em torno de trabéculas ósseas e infiltrado inflamatório polimorfonuclear (neutrófilos) focal e discreto (seta branca). Corte longitudinal, 100X. Figura 10. Imagem histológica do alvéolo dentário do grupo- tratado (com a presença da HAP-91) aos 30 dias. Observa-se a proliferação celular osteoblástica em torno de cristais de HAP-91 (estrela negra) e osteonecrose associada à presença de HAP-91 (seta) com proliferação fibrovascular associada a um infiltrado inflamatório polimorfonuclear (neutrófilo) acentuado (estrela branca). Corte longidudinal, 100X. 
Aos 50 dias, tanto o grupo-tratado como o grupocontrole demonstraram tecido ósseo imaturo (osteoide) com diversos ósteons, num processo de reparação óssea similar ao processo de mineralização com poucas áreas de tecido conjuntivo. Em ambos os grupos, não havia presença de reação inflamatória. No grupotratado, não se observou a presença da HAP-91, sendo sugerida sua biodegradação. Durante todo o experimento, não foram observadas partículas de HAP-91 no interior de macrófagos, como observado por Borges et al. (2000), nem células gigantes.

À análise histomorfométrica, constatou-se que o tecido ósseo aumentou progressivamente dos oito aos 50 dias, porém apenas aos 50 dias pôde- se observar o percentual de tecido ósseo maior que o de tecido conjuntivo, em ambos os grupos. (Tab. 4). No oitavo dia, houve uma diferença significativa na quantidade de tecido ósseo no grupo-tratado, se comparado ao grupo-controle, podendo-se, assim, afirmar que a HAP-91, associada à membrana de celulose bacteriana, promoveu um adiantamento no processo da reparação óssea nesses primeiros dias. Esse aumento de tecido ósseo no início do processo de reparação é um fator benéfico para o animal, principalmente nos casos de extensa perda do osso alveolar, pois apenas a formação de tecido de granulação no local deixa-o mecanicamente frágil, sendo que a substituição por um tecido mais resistente (o tecido ósseo) o quanto antes é o mais desejável.

Tabela 4. Médias e desvio-padrão das porcentagens de tecido ósseo e de tecido conjuntivo e hidroxiapatita (HA) nos alvéolos dentários dos grupos tratado e controle aos oito, 30 e 50 dias após extração e/ou implantação de HA e membrana de celulose bacteriana

\begin{tabular}{lllll}
\hline Dias & Grupo & Tecido ósseo & Tecido conjuntivo & Hidroxiapatita \\
\hline 8 & Tratado & $10,25 \pm 1,70 \mathrm{a}$ & $29,25 \pm 3,09 \mathrm{~b}$ & $60,5 \pm 3,69$ \\
& Controle & $4,75 \pm 2,50 \mathrm{~b}$ & $93,75 \pm 2,06 \mathrm{a}$ & \\
30 & Tratado & $22,05 \pm 4,79 \mathrm{~b}$ & $61,0 \pm 6,68 \mathrm{~b}$ & $16,5 \pm 3,41$ \\
& Controle & $37,75 \pm 1,70 \mathrm{a}$ & $62,25 \pm 1,70 \mathrm{a}$ & \\
\multirow{2}{*}{50} & Tratado & $91,0 \pm 3,26 \mathrm{a}$ & $9,0 \pm 3,26 \mathrm{a}$ & \\
& Controle & $94,25 \pm 2,98 \mathrm{a}$ & $5,75 \pm 2,98 \mathrm{a}$ & \\
\hline
\end{tabular}

Letras minúsculas diferentes na mesma coluna dentro do mesmo dia sinalizam diferença significativa entre os grupos pelo teste Mann-Whitney $(\mathrm{P}<0,05)$.

A presença da hidroxiapatita associada à membrana de celulose bacteriana pode ter auxiliado o processo de neoformação óssea nos oito primeiros dias neste experimento, não podendo ser afirmado o mesmo fato até aos 30 dias, quando se percebeu um atraso significativo na evolução do reparo alveolar do grupo-tratado quando comparado ao grupo-controle. $\mathrm{O}$ atraso também foi observado aos 21 e 42 dias por Brandão (2002) e aos 60 dias por Resende (1991), que utilizaram apenas a hidroxiapatita. Já aos 50 dias neste experimento, não foi observada diferença estatística de tecido ósseo entre os grupos tratado e controle, apresentando quantidade de tecido ósseo semelhante, sendo que o tempo necessário para a regeneração óssea completa não foi menor com a presença da HAP91 e da membrana de celulose bacteriana.

\section{CONCLUSÕES}

Houve biocompatibilidade da HAP-91 no osso alveolar dos felinos. A HAP-91 associado à membrana de celulose bacteriana, ou seja, no grupo tratado, quando comparado ao grupocontrole, promoveu um adiantamento no processo de reparação óssea aos oito dias de pósoperatório e um atraso aos 30 dias, porém aos 50 dias ambos os grupos apresentavam uma área de tecido ósseo semelhante. Assim, a HAP-91 pode ser utilizada como substituto ósseo em alvéolos de felinos, pois se integrou ao tecido do leito receptor, como também a membrana de celulose bacteriana pode ser utilizada na cavidade oral em felinos. Novos estudos com um período mais prolongado de avaliações se fazem necessários para se verificar os efeitos da HAP-91 na manutenção da crista alveolar após exodontia. 


\section{AGRADECIMENTOS}

À Capes, pela concessão da bolsa de estudos; às empresas Vetbrands e Centagro, pela doação de medicamentos; a Hernane da Silva Barud, pela doação da membrana de celulose bacteriana; à FAPEMIG e ao JHS Laboratório Químico Ltda., pelo fornecimento da HAP-91.

\section{REFERÊNCIAS}

ARAKAKI, E.T.M., YAMASHITA, S., MUTAF, M. Onlay silicone and hydroxyapatitetricalciumphosphate composite (HAP-TCP) blocks interfere with nasal bone growth in rabbits. Cleft Palate-Cran. J.,v.32, p.282-289, 1995.

BORGES, A.P.B.; RESENDE, C.M.F.; RIBEIRO, M.F.B. et al. Hidroxiapatita sintética como substituto ósseo em defeito experimental provocado no terço proximal da tíbia de cão: aspectos à microscopia de transmissão. Arq. Bras. Med. Vet. Zootec., v.52, p.616620,2000

BRANDÃO, A.C.; BRENTEGANI, L.G.; NOVAES Jr., A.B. et al. Histomorphometric analisys of rat alveolar wound healing with hydroxyapatite alone or associated to BMPs. Braz. Dent. J., v.13, p.147-154, 2002.

DUARTE T.S.; BORGES, A.P.B.; LAVOR, M.S.L. et al. Osteointegração da hidroxiapatita sintética no processo alveolar de mandíbula de cães: aspectos histológicos. Arq. Bras. Med. Vet. Zootec., v.58, p.849-853, 2006.

DUARTE, T.S. Osteointegração da hidroxiapatita sintética no processo alveolar da mandíbula de cães. 2003. 60f. Dissertação (Mestrado em Medicina Veterinária) - Departamento de Veterinária, Universidade Federal de Viçosa, Viçosa, MG.

EMILY, P.; SAN ROMÁN, F.; TROBO, J.I. et al. Periodontia. Enfermidade Periodontal. In: SAN ROMÁN, F.S. Atlas de odontologia de pequenos animais. São Paulo: Manole, 1999. p.111-112.
LINS, R.D.A.; PEQUENO, M.T.; MELO, J.P.L.C. et al. Atividade ósteo-reabsortiva na doença periodontal: O papel das citocinas e prostaglandinas. Rev. Cir. Traumat. Buco-Maxilo-Facial, v.7, p.29-36, 2006.

NOVAES Jr., A.B.; PAPALEXIOU, V.; LUCZYSZYN, S.M. et al. Immediate implant in extraction socket with acellular dermal matrix graft and bioactive glass: a case report. Imp. Dent., v.11, p.343-348, 2002.

PEREIRA, M.M.; VASCONCELOS, W.L.; ZAVAGLIA, C.A.C. Materiais cerâmicos- Ciência e aplicação em biomateriais. In: ORÉFICE, R.L.; PEREIRA, M.M.; MANSUR, H.S. Biomateriais Fundamentos e Aplicações. Rio de Janeiro:Cultura Médica, 2006. p.60-81.

RESENDE, C.M.F. Teste in vivo de biomateriais e histotecnia. In: ORÉFICE, R.L.; PEREIRA, M.M.; MANSUR, H.S. Biomateriais Fundamentos $e$ Aplicações. Rio de Janeiro: Cultura Médica, 2006. p.299-313.

RESENDE, V.L.S. Verificação do comportamento do osso alveolar implantado com hidroxiapatita através de exames clínicos, radiográficos e histológicos. Estudo feito em cão. 1991. 85f. Dissertação (Mestrado em Odontologia) - Universidade Federal de Minas Gerais, Belo Horizonte, MG.

ROUSH, J.K. Biomateriais e implantes cirúrgicos. In: SLATTER, D. Manual de cirurgia de pequenos animais. 3.ed. São Paulo:Manole, 2007. p.141-155.

ZENÓBIO, E.G.; MARCANTONIO, R.A.C.; MARCANTONIO, J.R.E. et al. Avaliação do comportamento biológico de dois materiais sintéticos, à base de fosfato de cálcio (Bioapatita ${ }^{\circledR}$ e Osteogen ${ }^{\circledR}$ ) após a implantação em alvéolos de cães. ROU UNESP, v.27, p.73-85, 1998. 